\title{
A new Type of Fuzzy Functions in Fuzzy Topological Spaces
}

\author{
Assist. Prof. Dr. Munir Abdul Khalik Alkhafaji \\ Al-Mustansiriyah University College of Education Department of Math.
}

Abstract: In this paper, we introduce and study some characterization and some properties of fuzzy continuous functions ( Fuzzy super continuous functions) from fuzzy topological space into another fuzzy topological space has its bases on the notation of quasi-coincidence, quasi-neighborhood, fuzzy $\delta$-closure and $\theta$-neighborhood.

\section{Introduction}

The first publications in fuzzy set theory by Zadeh [11] show the intention of the authors to generalize the classical notion of a set and proposition (Statement) to accommodate fuzziness, Chang [4], Wong [9], [10] and other applied some basic concepts from general topology to fuzzy sets and developed a theory of fuzzy topological spaces in 1980, pu and liu [8], introduced the concepts of quasi-coincidence and quasi-neighborhood

\section{Preliminaries}

We will discuss some fundamental notions and basic concepts related to fuzzy topological space.

\section{Definition 2 - 1}

A fuzzy topology is a family $\tilde{\mathrm{T}}$ of fuzzy sets $\mathrm{X}$ ( $\mathrm{X}$ be any set of elements) which satisfying the following conditions:

1 - O , 1 ( i.e. $\varnothing$ and $\mathrm{X}) \in \tilde{\mathrm{T}}$,

2- If $\tilde{\mathrm{A}}, \tilde{\mathrm{B}} \in \tilde{\mathrm{T}}$, then $\tilde{\mathrm{A}} \cap \widetilde{\mathrm{B}} \in \tilde{\mathrm{T}}$

3- If $\widetilde{\mathrm{A}}_{\mathrm{i}} \in \tilde{\mathrm{T}}$ for each $\mathrm{i} \in \mathrm{I}$ (where $\mathrm{I}$ is the index set), then $\bigcup_{\mathrm{i} \in \mathrm{I}} \tilde{\mathrm{A}}_{\mathrm{i}} \in \tilde{\mathrm{T}}$.

$\widetilde{\mathrm{T}}$ is called a fuzzy topology for $\mathrm{X}$, and the pair $(\mathrm{X}, \tilde{\mathrm{T}})$ is a fuzzy topological space. Every member of $\tilde{\mathrm{T}}$ is called $\tilde{\mathrm{T}}$ - open fuzzy set. A fuzzy set $\tilde{\mathrm{C}}$ in $\mathrm{X}$ is a $\tilde{\mathrm{T}}$ - closed fuzzy set if and only if its complement $\tilde{\mathrm{C}}^{\mathrm{C}}$ is a $\tilde{\mathrm{T}}$ - open fuzzy set.

\section{Definition $2-2$}

A fuzzy set $\widetilde{A}$ in a fuzzy topological space ( $X, \widetilde{T}$ ) is said to be quasi-coincident ( $q$ - coincident, for short ) with fuzzy set $\widetilde{B}$, denoted by $\widetilde{A} q \widetilde{B}$,

If and only if there exist $X \in X$ such that $\mu_{\tilde{\mathrm{A}}(\mathrm{x})}+\mu_{\mathrm{B}} \square_{(\mathrm{x})}>1$.

Definition $2-3$

A fuzzy set $\tilde{\mathrm{A}}$ in a fuzzy topological space ( $\mathrm{X}, \tilde{\mathrm{T}}$ ) is said to be quasi - neighborhood ( $\mathrm{q}-\mathrm{nbd}$, for thort ) of a fuzzy point $\mathrm{X}_{\alpha}$ ( where $\mathrm{x}$ is the support and $\alpha$ is the value of the fuzzy point, $0<\alpha \leq 1$ )if and only if there exists open fuzzy set $\tilde{\mathrm{B}}$ such that $\mathrm{X}_{\alpha} \mathrm{q} \tilde{\mathrm{B}} \subseteq \tilde{\mathrm{A}}$.

Definition $2-4$

Two fuzzy sets $\widetilde{\mathrm{A}}, \widetilde{\mathrm{B}}$ in fuzzy topological space $(\mathrm{X}, \tilde{\mathrm{T}}), \tilde{\mathrm{A}} \subseteq \tilde{\mathrm{B}}$ if and only if $\widetilde{\mathrm{A}}$ is not q- coincident with $\widetilde{\mathrm{B}}^{\mathrm{c}}$ ( complement of $\widetilde{\mathrm{B}}$ ) and denoted by $\widetilde{\mathrm{A}} \mathrm{qB} \widetilde{\mathrm{B}}^{\mathrm{c}}$. 


\section{Definition $2-5$}

A fuzzy point $\mathrm{X}_{\alpha} \in \overline{\widetilde{\mathrm{A}}}$ ( the fuzzy closure of fuzzy set $\tilde{\mathrm{A}}$ in an fuzzy topological space ( $\mathrm{X}, \tilde{\mathrm{T}}$ ) if and only if each $\mathrm{q}-$ nbd of $\mathrm{X}_{\alpha}$ is $\mathrm{q}$ - coincident with $\tilde{\mathrm{A}}$.

Definition 2 - 6

A fuzzy set $\widetilde{\mathrm{A}}$ in fuzzy topological space ( $\mathrm{X}, \widetilde{\mathrm{T}}$ ) is called open ( closed ) fuzzy regularly if and only if $(\overline{\widetilde{A}})^{\circ}=\tilde{\mathrm{A}}\left(\tilde{\mathrm{A}}^{\mathrm{o}}\right.$ the fuzzy interior of fuzzy set $\left.\overline{\mathrm{A}}_{\text {in an fuzzy topological space }}(\mathrm{X}, \tilde{\mathrm{T}})\right)$ (respectively $\left.\left(\overline{\tilde{\mathrm{A}}^{\mathrm{o}}}\right)=\tilde{\mathrm{A}}\right)$.

Definition $2-7$

A fuzzy point $\mathrm{X}_{\alpha}$ is called a fuzzy $\delta$ - cluster point of a fuzzy set $\widetilde{\mathrm{A}}$ in an fuzzy topological space ( $\mathrm{X}, \tilde{\mathrm{T}}$ ) if and only if every open fuzzy regularly q-nbd of $\mathrm{X}_{\alpha}$ is $\mathrm{q}$ - coincident with $\tilde{\mathrm{A}}$.

Definition 2 - 8

The set of all fuzzy $\delta$-cluster points of $\tilde{\mathrm{A}}$ is called the fuzzy $\delta$-cluster of $\widetilde{\mathrm{A}}$, to be denoted by $[\tilde{\mathrm{A}}]_{\delta}$.

Remark 2 - 1

A fuzzy set $\tilde{\mathrm{A}}$ is fuzzy $\delta$-closed if and only if $\tilde{\mathrm{A}}=[\tilde{\mathrm{A}}]_{\delta}$ and complement of a fuzzy $\delta$-closed is called fuzzy $\delta$ - open.

Definition 2 - 9

If $\mathrm{X}, \mathrm{Y}$ are fuzzy topological spaces and $\tilde{\mathrm{A}}, \widetilde{\mathrm{B}}$ are fuzzy sets of $\mathrm{X}$ and $\mathrm{Y}$ respectively, then the fuzzy set

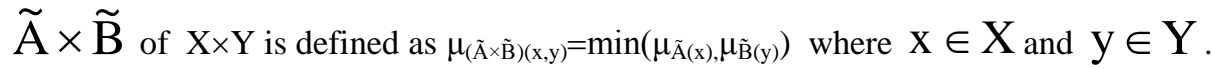

Throughout the paper, by ( $X, \tilde{T}),\left(Y, \widetilde{T}_{1}\right.$ ) etc. or simply by $X, Y, Z$, etc. we shall mean fuzzy topological spaces.

\section{Definition 3 - 1}

\section{Fuzzy Super Continuous Functions}

A mapping $\mathrm{f}: \mathrm{X} \rightarrow \mathrm{Y}$ from fuzzy topological $\mathrm{X}$ to an fuzzy topological space $\mathrm{Y}$ is said to be fuzzy super continuous at a fuzzy point $X_{\alpha}$ of $X$ if and only if for every $q-\operatorname{nbd} \tilde{U}$ of $f\left(X_{\alpha}\right)$, there is a $q-\operatorname{nbd} \tilde{V}$ of $X_{\alpha}$ such that $\mathrm{f}(\overline{\tilde{V}})^{\mathrm{o}} \subseteq \mathrm{U}$ ( equivalently, we can take $\tilde{\mathrm{U}}, \tilde{\mathrm{V}}$ to be open fuzzy set ). f is said to be fuzzy super continuous on $\mathrm{X}$ if and only if it is fuzzy super continuous at each fuzzy point of $\mathrm{X}$.

Definition 3 - 2

A function $\mathrm{f}: \mathrm{X} \longrightarrow \mathrm{Y}$ from an fuzzy topological space $\mathrm{X}$ to an fuzzy topological space $\mathrm{Y}$ is said to be fuzzy continuous at a fuzzy point $X_{\alpha}$ of $X$ if and only if for every $q-\operatorname{nbd} \tilde{U}$ of $f\left(X_{\alpha}\right)$ there is a q-nbd $\tilde{V}$ of $X_{\alpha}$ such that $\mathrm{f}(\tilde{\mathrm{V}}) \subseteq \tilde{\mathrm{U}}$. $\mathrm{f}$ is called fuzzy continuous on $\mathrm{X}$ if and only if $\mathrm{f}$ is fuzzy continuous at each fuzzy point of X. 


\section{Remark 3 - 1}

If a mapping $\mathrm{f}:(\mathrm{X}, \quad \tilde{\mathrm{T}}) \longrightarrow(\mathrm{Y}, \quad \tilde{\mathrm{F}}) \quad$, from an fuzzy topological space $(\mathrm{X}, \tilde{\mathrm{T}})$ to an fuzzy topological space $\left(\mathrm{Y}, \tilde{\mathrm{F}}_{)}\right)$is fuzzy super continuous at a fuzzy point $\mathrm{X}_{\alpha}$ of $\mathrm{X}$, then $\mathrm{f}$ is fuzzy continuous at $\mathrm{X}_{\alpha}$, but the converse is false.

\section{Theorem 3 - 1}

For a mapping $\mathrm{f}:(\mathrm{X}, \widetilde{\mathrm{T}}) \longrightarrow(\mathrm{Y}, \tilde{\mathrm{F}})$, from an fuzzy topological space $(\mathrm{X}, \widetilde{\mathrm{T}})$ to an fuzzy topological space $(\mathrm{Y}, \tilde{\mathrm{F}})$, the following are equivalent:

(a) $f$ is a fuzzy super continuous .

(b) $\mathrm{f}\left([\tilde{\mathrm{A}}]_{\delta}\right) \subseteq \overline{\mathrm{f}(\tilde{\mathrm{A}})}$, for every fuzzy set $\tilde{\mathrm{A}}$ in $\mathrm{X}$.

(c) $\left[\mathrm{f}^{-1}(\tilde{\mathrm{A}})\right]_{\delta} \subseteq \mathrm{f}^{-1}(\overline{\widetilde{A}})$, for every fuzzy set $\tilde{\mathrm{A}}$ in $\mathrm{Y}$.

(d) For every closed fuzzy set $\widetilde{\mathrm{A}}$ in $\mathrm{Y}, \mathrm{f}^{-1}(\widetilde{\mathrm{A}})$ is fuzzy $\delta$-closed in $\mathrm{X}$.

(e) For every open fuzzy set $\widetilde{\mathrm{A}}$ in $\mathrm{Y}, \mathrm{f}^{-1}(\widetilde{\mathrm{A}})$ is fuzzy $\delta$-open in $\mathrm{X}$.

(f) For every open fuzzy point $\mathrm{X}_{\alpha}$ of $\mathrm{X}$ and for each open fuzzy q-nbd $\tilde{\mathrm{M}}$ of $\mathrm{f}\left(\mathrm{X}_{\alpha}\right)$, there is a fuzzy $\delta$ - open q-nbd $\tilde{\mathrm{N}}$ of $\mathrm{x}_{\alpha}$ such that $\mathrm{f}(\tilde{\mathrm{N}}) \subseteq \tilde{\mathrm{M}}$.

Proof. (a) $\rightarrow$ (b) :

Let $\mathrm{X}_{\alpha} \in[\tilde{\mathrm{A}}]_{\delta}$ and $\tilde{\mathrm{U}}$ be any open fuzzy q-nbd of $\mathrm{y}_{\alpha}=\mathrm{f}\left(\mathrm{x}_{\alpha}\right)$, where $\mathrm{y}=\mathrm{f}(\mathrm{x})$.

By (a), there is open fuzzy q-nbd $\tilde{\mathrm{N}}$ of $\mathrm{x}_{\alpha}$ such that $\mathrm{f}(\overline{\tilde{\mathrm{N}}})^{\mathrm{o}} \subseteq \tilde{\mathrm{U}}$.

Now , if $\mathrm{X}_{\alpha} \in[\tilde{\mathrm{A}}]_{\delta}$ then $(\overline{\tilde{\mathrm{N}}})^{\mathrm{o}} \mathrm{q} \tilde{\mathrm{A}}$ so that

$\mathrm{f}(\overline{\tilde{N}})^{\mathrm{o}} \mathrm{q} \mathrm{f}(\tilde{\mathrm{A}})$ and hence $\tilde{\mathrm{Uq}} \mathrm{f}(\tilde{\mathrm{A}})$.

Therefore $\mathrm{f}\left(\mathrm{x}_{\alpha}\right) \in \overline{(\mathrm{f}(\widetilde{\mathrm{A}}))}$ and it follows that

$$
\mathrm{x}_{\alpha} \in \mathrm{f}^{-1}(\overline{\mathrm{f}(\tilde{\mathrm{A}}))} \text {. }
$$

Thus $[\tilde{\mathrm{A}}]_{\delta} \subseteq \mathrm{f}^{-1}(\overline{\mathrm{f}(\tilde{\mathrm{A}})})$ and hence $\mathrm{f}\left([\tilde{\mathrm{A}}]_{\delta}\right) \subseteq \overline{\mathrm{f}(\tilde{\mathrm{A}})}$.

(b) $\rightarrow$ (c) :

By (b) , if $\mathrm{f}\left(\left[\mathrm{f}^{-1}(\tilde{\mathrm{A}})\right]_{\delta}\right) \subseteq \overline{\mathrm{f}\left[\mathrm{f}^{-1}(\tilde{\mathrm{A}})\right]} \subseteq \overline{\tilde{\mathrm{A}}}$

Then it follows that $\left[\mathrm{f}^{-1}(\tilde{\mathrm{A}})\right]_{\delta} \subseteq \mathrm{f}^{-1}(\overline{\widetilde{\mathrm{A}}})$.

(c) $\rightarrow$ (d) : Immediate

(d) $\rightarrow$ (e) : Clear

(e) $\rightarrow$ (f) : $\tilde{\mathrm{N}}=\mathrm{f}^{-1}(\tilde{\mathrm{M}})$ serves the purpose.

(f) $\rightarrow$ (a) : For any fuzzy point $\mathrm{X}_{\alpha}$ and open fuzzy q-nbd $\tilde{\mathrm{V}}$ of $\mathrm{f}\left(\mathrm{X}_{\alpha}\right)$, there is a fuzzy $\delta$ - open q-nbd $\tilde{\mathrm{N}}$ of $\mathrm{x}_{\alpha}$ such that $\mathrm{f}(\tilde{\mathrm{N}}) \subseteq \tilde{\mathrm{V}}$.

Then $1-\tilde{\mathrm{N}}=\widetilde{\mathrm{G}}$ ( say ) is fuzzy $\delta$-closed in $\mathrm{X}$ and $\mathrm{x}_{\alpha} \notin \widetilde{\mathrm{G}}$.

So the exist a open fuzzy regularly q-nbd $\tilde{\mathrm{M}}$ of $\mathrm{x}_{\alpha}$ such that $\tilde{\mathrm{M}}$ is not q-coincident with $\tilde{\mathrm{G}}$. 
Now, $x_{\alpha} q \tilde{\mathrm{M}} \rightarrow \mathrm{x}_{\alpha} \mathrm{q}(\overline{\tilde{\mathrm{M}}})^{\mathrm{o}} \subseteq 1-\tilde{\mathrm{G}}=\tilde{\mathrm{N}}$

From which it follows that $\mathrm{f}(\overline{\tilde{M}})^{\mathrm{o}} \subseteq \mathrm{f}(\tilde{\mathrm{N}}) \subseteq \tilde{\mathrm{V}}$ and thus $\mathrm{f}$ is fuzzy super continuous.

\section{Theorem 3-2}

A function $\mathrm{f}: \mathrm{X} \rightarrow \mathrm{Y}$ from fuzzy is a fuzzy super continuous if and only if for any fuzzy point $\mathrm{X}_{\alpha}$ of $\mathrm{X}$ and for each q-nbd $\tilde{\mathrm{M}}$ of $\mathrm{f}\left(\mathrm{x}_{\alpha}\right)$, there q q-nbd $\tilde{\mathrm{N}}$ of $\mathrm{x}_{\alpha}$ such that $\mathrm{f}\left(\overline{\tilde{\mathrm{N}}}^{\mathrm{o}}\right)^{\mathrm{o}} \subseteq \tilde{\mathrm{M}}$.

\section{Lemma 3 - 1}

Let $\mathrm{f}: \mathrm{X} \rightarrow \mathrm{Y}$ be a mapping from an fuzzy topological space $\mathrm{X}$ to an fuzzy topological space $\mathrm{Y}$ the following are equivalent:

(a) For any fuzzy point $\mathrm{X}_{\alpha}$ of $\mathrm{X}$ and for any q-nbd $\tilde{\mathrm{M}}$ of $\mathrm{f}\left(\mathrm{X}_{\alpha}\right)$, there is a q-nbd $\tilde{\mathrm{N}}$ of $\mathrm{X}_{\alpha}$ such that $\mathrm{f}\left(\overline{\tilde{\mathrm{N}}^{\mathrm{o}}}\right) \subseteq \tilde{\mathrm{M}}$

(b) For any fuzzy point $\mathrm{X}_{\alpha}$ of $\mathrm{X}$ and for any $\mathrm{q}-\mathrm{nbd} \tilde{\mathrm{M}}$ of $\mathrm{f}\left(\mathrm{X}_{\alpha}\right)$, there is a q-nbd $\tilde{\mathrm{N}}$ of $\mathrm{X}_{\alpha}$ such that $\mathrm{f}\left(\overline{\tilde{\mathrm{N}}^{\mathrm{o}}}\right) \subseteq \tilde{\mathrm{M}}$

Proof : it is immediate .

Corollary $3-1$

If one of the conditions of Lemma $3-1$ holds then $f$ is fuzzy super continuous.

That the converse of the above corollary is false is shown by the following example.

\section{Example 3 - 1}

Let $\mathrm{X}$ be a non-empty set and $\mathrm{a} \in \mathrm{X}$.

Consider $\widetilde{\mathrm{T}}=\{0,1, \widetilde{\mathrm{A}}\}$,

Where $\mu_{\tilde{\mathrm{A}}}(\mathrm{a})=1 / 3$ and $\mu_{\tilde{\mathrm{A}}}(\mathrm{x})=0$, for $\mathrm{X} \neq \mathrm{a}(\mathrm{X} \in \mathrm{X})$, and consider the identity map

$\mathrm{f}:(\mathrm{X}, \tilde{\mathrm{T}}) \rightarrow(\mathrm{X}, \tilde{\mathrm{T}})$.

We consider the fuzzy point $\mathrm{a}_{\alpha}$ of $\mathrm{X}$, where $\alpha=\frac{5}{6}$.

Then $\tilde{\mathrm{A}}$ is open fuzzy q-nbd of $\mathrm{f}\left(\mathrm{a}_{\alpha}\right)$,

But $\mathrm{f}\left(\overline{\tilde{\mathrm{U}}^{\mathrm{o}}}\right) \supset \tilde{\mathrm{A}}$, for $\tilde{\mathrm{U}}=\tilde{\mathrm{A}}$ or 1 .

Hence condition (a) of lemma $3-1$ fails. But if clearly fuzzy super continuous.

Lemma 3 - 2

Let $\mathrm{A}, \mathrm{X}, \mathrm{Y}$ be fuzzy topological spaces and $\mathrm{f}_{1}: \mathrm{A} \rightarrow \mathrm{X}$ and $\mathrm{f}_{2}: \mathrm{A} \rightarrow \mathrm{Y}$ be any functions .

Let $\mathrm{f}: \mathrm{A} \rightarrow \mathrm{X} \times \mathrm{Y}$ be defined by $\mathrm{f}(\mathrm{a})=\left(\mathrm{f}_{1}(\mathrm{a}), \mathrm{f}_{2}(\mathrm{a})\right)$, for $\mathrm{a} \in \mathrm{A}$ where $\mathrm{X} \times \mathrm{Y}$ is provided with the product fuzzy topology.

(a) If $\tilde{B}, \tilde{U}_{1}, \tilde{U}_{2}$ are fuzzy sets in $A, X$ and $Y$ respectively such that $\mathrm{f}(\tilde{\mathrm{B}}) \subseteq \tilde{\mathrm{U}}_{1} \times \tilde{\mathrm{U}}_{2}$ then $\mathrm{f}_{1}(\tilde{\mathrm{B}}) \subseteq \tilde{\mathrm{U}}_{1}$ and $\mathrm{f}_{2}(\tilde{\mathrm{B}}) \subseteq \tilde{\mathrm{U}}_{2}$ 
(b) If $\tilde{\mathrm{W}}$ is open fuzzy q-nbd of $\mathrm{f}\left(\mathrm{x}_{\alpha}\right)=\left(\mathrm{f}_{1}(\mathrm{x}), \mathrm{f}_{2}(\mathrm{x})\right)_{\alpha}$ in $\mathrm{X} \times \mathrm{Y}$,

Then there exist open fuzzy q-nbd $\tilde{\mathrm{U}}$ of $\left(\mathrm{f}_{1}(\mathrm{x})\right)_{\alpha}$ in $\mathrm{X}$ and open fuzzy q-nbd $\tilde{\mathrm{V}}$ of $\left(\mathrm{f}_{2}(\mathrm{x})\right)_{\alpha}$ in $\mathrm{Y}$ such that $\mathrm{f}\left(\mathrm{x}_{\alpha}\right) \mathrm{q}(\tilde{\mathrm{U}} \times \tilde{\mathrm{V}}) \subseteq \tilde{\mathrm{W}}$.

(c) If $\mathrm{f}_{1}\left(\tilde{\mathrm{A}}_{1}\right) \times \mathrm{f}_{2}\left(\tilde{\mathrm{A}}_{2}\right) \subseteq \tilde{\mathrm{U}}_{1} \times \tilde{\mathrm{U}}_{2}$, where $\tilde{\mathrm{A}}_{1}, \tilde{\mathrm{A}}_{2}$ are fuzzy sets in $\mathrm{A}$ and $\tilde{\mathrm{U}}_{1}, \tilde{\mathrm{U}}_{2}$ are fuzzy sets of $x$ and $y$ respectively, then $f(\tilde{V}) \subseteq \tilde{U}_{1} \times \tilde{U}_{2}$ where $\tilde{V}=\tilde{A}_{1} \cap \tilde{A}_{2}$.

Proof. (a) we prove that $\mathrm{f}_{1}(\tilde{\mathrm{B}}) \subseteq \tilde{\mathrm{U}}_{1}$.

In fact, Let $\mathrm{X} \in \mathrm{X}$, then

$\mathrm{f}\left(\mu_{\tilde{\mathrm{B}}}(\mathrm{x})\right)=\operatorname{Sup}_{\mathrm{z} \in \mathrm{f}_{1}^{-1}(\mathrm{x})} \mu_{\tilde{\mathrm{B}}}(\mathrm{x})$

Now, $\mathrm{z} \in \mathrm{f}_{1}^{-1}(\mathrm{x}) \rightarrow \mathrm{f}_{1}(\mathrm{z})=\mathrm{x}$.

Let $\mathrm{f}_{2}(\mathrm{z})=\mathrm{y}_{1} \in \mathrm{Y}$. Then

$\mathrm{f}(\mathrm{z})=\left(\mathrm{x}, \mathrm{y}_{1}\right) \rightarrow \mathrm{z} \in \mathrm{f}^{-1}\left[\left(\mathrm{x}, \mathrm{y}_{1}\right)\right] \rightarrow(1)$

Now

$\mathrm{f}\left(\mu_{\tilde{B}}\right)[(\mathrm{x}, \mathrm{y})]=\operatorname{Sup}_{t \in \mathrm{f}^{-1}\left[\left(\mathrm{x}, \mathrm{y}_{1}\right)\right]} \tilde{\mu_{\mathrm{B}}(\mathrm{t})}$

Obviously

$\mu_{\tilde{\mathrm{B}}}(\mathrm{z}) \subseteq \operatorname{Sup}_{\mathrm{t} \in \mathrm{f}^{-1}\left[\left(\mathrm{x}, \mathrm{y}_{1}\right)\right]} \mu_{\tilde{\mathrm{B}}}(\mathrm{t})$

By (1).

But

$$
\begin{gathered}
\operatorname{Sup}_{\mathrm{t} \in \mathrm{f}^{-1}\left[\left(\mathrm{x}, \mathrm{y}_{1}\right)\right]} \mu_{\tilde{\mathrm{B}}}(\mathrm{t}) \subseteq \mu\left(\tilde{\mathrm{U}}_{1} \times \tilde{\mathrm{U}}_{2}\right)\left[\left(\mathrm{x}, \mathrm{y}_{1}\right)\right] \rightarrow \mu_{\tilde{\mathrm{B}}}(\mathrm{z}) \subseteq \mu_{\tilde{\mathrm{U}}_{1} \times \tilde{\mathrm{U}}_{2}}\left[\left(\mathrm{x}, \mathrm{y}_{1}\right)\right] \\
\rightarrow \mu_{\tilde{\mathrm{B}}}(\mathrm{z}) \subseteq \mu_{\tilde{\mathrm{U}}_{1}}(\mathrm{x})
\end{gathered}
$$

Since (2) is true for all $\mathrm{z} \in \mathrm{f}_{1}^{-1}(\mathrm{x})$, we have $\mathrm{f}_{1}\left(\mu_{\tilde{\mathrm{B}}}\right)(\mathrm{x}) \subseteq \mu_{\tilde{\mathrm{U}}_{1}}(\mathrm{x})$ and hence $\quad \mathrm{f}_{1}(\tilde{\mathrm{B}}) \subseteq \tilde{\mathrm{U}}_{1}$.

Similarly, we can prove that $\mathrm{f}_{2}(\tilde{\mathrm{B}}) \subseteq \tilde{\mathrm{U}}_{2}$.

(b) Since $\tilde{W}$ is open fuzzy set in $X \times Y$, we have $\tilde{W}=\cup\left(\tilde{U}_{\beta} \times \tilde{V}_{\mu}\right)$, where the $\tilde{U}_{\beta}$,s are open set in $\mathrm{X}$ and the $\tilde{\mathrm{V}}_{\mu}$ 's are open fuzzy set in $\mathrm{Y}$.

Then obviously $\tilde{\mathrm{U}}_{\beta} \times \tilde{\mathrm{V}}_{\mu} \subseteq \tilde{\mathrm{W}}$, for each $\beta$ and each $\mu$.

We claim that for some $\beta$ and some $\mu$.

$\mathrm{f}\left(\mathrm{x}_{\alpha}\right) \mathrm{q} \tilde{\mathrm{U}}_{\beta} \times \tilde{\mathrm{V}}_{\mu}$

In not then for each $\beta$ and each $\mu$

$\alpha+\min \left(\mu_{\tilde{U}_{\beta}}\left(f_{1}(x)\right), \mu_{\tilde{V}_{\mu}}\left(f_{2}(x)\right) \leq 1\right.$

So that $\alpha+\mu_{\left(\tilde{U}_{\beta} \times \tilde{V}_{\mu}\right)}(f(x)) \leq 1$, for each $\beta$ and each $\mu$, 
And thus $\alpha+\operatorname{Sup}\left[\mu_{\left(\tilde{U}_{\beta} \times \tilde{V}_{\mu}\right)}(\mathrm{f}(\mathrm{x})) \leq 1\right.$.

But then $\alpha+\mu_{\tilde{\mathrm{w}}}(\mathrm{f}(\mathrm{x})) \leq 1$ and hence $\mathrm{f}\left(\mathrm{x}_{\alpha}\right) \mathrm{q} \tilde{\mathrm{W}}$, a contradiction .

Therefore $f\left(x_{\alpha}\right) q \tilde{U}_{\beta} \times \tilde{V}_{\mu}$, for some $\beta$ and some $\mu$,

So that $\alpha+\min \left(\mu_{\tilde{U}_{\beta}}\left(f_{1}(x)\right), \mu_{\tilde{V}_{\mu}}\left(f_{2}(x)\right)>1\right.$.

Then $f_{1}\left(x_{\alpha}\right) q \tilde{U}_{\beta}$ and $f_{2}\left(x_{\alpha}\right) q \tilde{V}_{\mu}$ we have proved our desired result.

(c) Straight forward and left.

\section{Theorem 3 - 3}

Let $A, X, Y$ be fuzzy topological spaces and $f_{1}: A \rightarrow X, f_{2}: A \rightarrow Y$ be any functions. Then $\mathrm{f}: \mathrm{A} \rightarrow \mathrm{X} \times \mathrm{Y}$, defined by

$\mathrm{f}(\mathrm{x})=\left(\mathrm{f}_{1}(\mathrm{x}), \mathrm{f}_{2}(\mathrm{x})\right)$, for all $\mathrm{x} \in \mathrm{A}$, is fuzzy super continuous iff $\mathrm{f}_{1}$ and $\mathrm{f}_{2}$ are fuzzy super continuous.

\section{Proof.}

Let $\mathrm{X}_{\alpha}$ be a fuzzy point of $\mathrm{A}$ and $\tilde{\mathrm{U}}_{1}, \tilde{\mathrm{U}}_{2}$ be open fuzzy q-nbds of $\mathrm{f}_{1}\left(\mathrm{x}_{\alpha}\right)$ and $\mathrm{f}_{2}\left(\mathrm{x}_{\alpha}\right)$ in $\mathrm{X}$ and $\mathrm{Y}$ respectively.

Then $\tilde{\mathrm{U}}_{1} \times \tilde{\mathrm{U}}_{2}$ is clearly open fuzzy q-nbd of $\mathrm{f}\left(\mathrm{x}_{\alpha}\right)$.

i.e., of $(\mathrm{f}(\mathrm{x}))_{\alpha}$.

Then by fuzzy super continuity of $\mathrm{f}$, there is open fuzzy q-nbd $\tilde{\mathrm{V}}$ of $\mathrm{X}_{\alpha}$ in $\mathrm{A}$ such that $\mathrm{f}(\overline{\tilde{\mathrm{V}}})^{\mathrm{o}} \subseteq \tilde{\mathrm{U}}_{1} \times \tilde{\mathrm{U}}_{2}$.

By lemma 3 - 2 (a), we then have

$$
\mathrm{f}_{1}(\overline{\tilde{\mathrm{V}}})^{\mathrm{o}} \subseteq \tilde{\mathrm{U}}_{1} \text { and } \mathrm{f}_{2}(\overline{\tilde{\mathrm{V}}})^{\mathrm{o}} \subseteq \tilde{\mathrm{U}}_{2}
$$

So that $\mathrm{f}_{1}$ and $\mathrm{f}_{2}$ are fuzzy super continuous conversely,

Let $X_{\alpha}$ be any fuzzy point of $A$ and $\tilde{W}$ be any open fuzzy q-nbd of $f\left(X_{\alpha}\right)$ in $X \times Y$.

Then by lemma $3-2(b)$, there exist open fuzzy q-nbds $\tilde{U}_{1}$ of $f_{1}\left(x_{\alpha}\right)$ and $\tilde{U}_{2}$ of $f_{2}\left(x_{\alpha}\right)$ such that $\mathrm{f}\left(\mathrm{x}_{\alpha}\right) \mathrm{q} \tilde{\mathrm{U}}_{1} \times \tilde{\mathrm{U}}_{2} \subseteq \tilde{\mathrm{W}}$. Also since $\mathrm{f}_{1}$ and $\mathrm{f}_{2}$ are fuzzy super continuous, there exist open fuzzy q-nbd $\tilde{\mathrm{V}}_{1}$ and $\tilde{\mathrm{V}}_{2}$ of $\mathrm{x}_{\alpha}$ in A such that $\mathrm{f}_{1}\left(\overline{\tilde{\mathrm{V}}}_{1}\right)^{\mathrm{o}} \subseteq \tilde{\mathrm{U}}_{1}$ and $\mathrm{f}_{2}\left(\overline{\tilde{\mathrm{V}}}_{2}\right)^{\mathrm{o}} \subseteq \tilde{\mathrm{U}}_{2}$, so that $\mathrm{f}_{1}\left(\overline{\tilde{\mathrm{V}}}_{1}\right)^{\mathrm{o}} \times \mathrm{f}_{2}\left(\overline{\tilde{\mathrm{V}}}_{2}\right)^{\mathrm{o}} \subseteq \tilde{\mathrm{U}}_{1} \times \tilde{\mathrm{U}}_{2}$

Now by lemma $3-2$ (c) we have $\mathrm{f}(\overline{\tilde{V}})^{\mathrm{o}} \subseteq \tilde{\mathrm{U}}_{1} \times \tilde{\mathrm{U}}_{2}$, where $\tilde{\mathrm{V}}=\tilde{\mathrm{V}}_{1} \cap \tilde{\mathrm{V}}_{2}$ and $\tilde{\mathrm{V}}$ is obviously open fuzzy q-nbd .

Hence $f$ is fuzzy super continuous function.

\section{References}

[1]. S.P. Arya and R. Gupta, on strongly continuous mapping, kyungpook Math. J. 14(2) (1974) $131-143$.

[2]. K.K. Azad, on fuzzy semi continuity, fuzzy almost continuity and fuzzy weakly continuity, J. Math. Anal. Appl. 82 (1) (1981) 14 32.

[3]. Casanovas J. Torrens, J., An axiomatic approach to fuzzy cardinalities of finite fuzzy sets , fuzzy sets and systems. 133 (2003), no.2, 193-209.

[4]. C.L. Chang, Fuzzy topological spaces, J. Math. Anal. Appl. 24 (1968) 182 - 190.

[5]. B. Hutton and I.L. Reilly, Separation axioms in fuzzy topological spaces, Fuzzy sets and systems 3 (1980) $127-141$.

[6]. N. Levine, strong continuity in topological spaces, Amer. Math monthly 67 (1960) 269.

\begin{tabular}{lll}
\hline DOI: $10.9790 / 5728-120501118124$ & www.iosrjournals.org & 123 |Page
\end{tabular}


[7]. S. Nada , on fuzzy topological spaces, Fuzzy sets and systems 19(1986) 193 - 197.

[8]. Pao - Ming Pu and Ying - Ming Liu, Fuzzy topology, In. Neighborhood structure of fuzzy point and Moore-smith convergence, J. Math. Anal. Appl. 76 (1980) $571-599$.

[9]. C.K. Wong, Fuzzy topology ; product and quotient theorems. J. Math. Anal. Appl. 45 (1974).

[10]. C.K. Wong, Fuzzy points and local properties of fuzzy topology , J. Math. Anal. Appl. 46 (1974) 316 - 328.

[11]. L.A. Zadeh, Fuzzy sets, inform, and control 8 (1965) $338-353$. 